\title{
Inhibitory Effect of Epinastine on Superoxide Generation by Rat Neutrophils
}

\author{
Nobuyuki Fukuishi ${ }^{1}$, Tomoko Kan ${ }^{1}$, Kimihisa Hirose ${ }^{1}$, Reiko Akagi ${ }^{2}$ and Masaaki Akagi ${ }^{1,}$ \\ 'Department of Pharmacology, Faculty of Pharmaceutical Sciences, Tokushima Bunri University, Tokushima 770, Japan \\ ${ }^{2}$ Department of Nutritional Science, Faculty of Health and Welfare Science, Okayama Prefectural University, Okayama 700, Japan
}

Received April 12, $1995 \quad$ Accepted June 8, 1995

\begin{abstract}
We studied the effects of antiallergic drugs, epinastine, ketotifen, oxatomide, mequitazine and cromolyn sodium on superoxide anion $\left(\mathrm{O}_{2}^{-}\right)$generation from rat neutrophils. Epinastine, ketotifen, oxatomide and mequitazine dose-dependently prevented the $\mathrm{N}$-formyl-Met-Leu-Phe- and phorbol 12 myristate 13-acetate-induced $\mathrm{O}_{2}$ generation, but cromolyn sodium did not prevent it. When membrane and cytosol fractions were incubated with each drug, epinastine, ketotifen and mequitazine prevented $\mathrm{O}_{2}{ }^{-}$ generation. On the other hand, when only the membrane fraction was incubated with each drug, ketotifen and mequitazine prevented $\mathrm{O}_{2}^{-}$generation, but epinastine did not. Epinastine may inhibit the NADPH oxidase system through the obstruction of NADPH oxidase-associated cytosol components.
\end{abstract}

Keywords: $\mathrm{O}_{2}{ }^{-}$generation, Epinastine, Neutrophil (rat)

Epinastine (WAL $801 \mathrm{CL}$ ) has been reported to show a potent inhibitory effect on the immediate type hypersensitivity reaction and antigen-induced histamine or SRS-A release from the lung pieces of actively sensitized guinea pigs $(1,2)$. Epinastine may be more potent than terfenadine or oxatomide in inhibiting the histamine-induced contraction of isolated guinea pig ileum. Furthermore, epinastine is more effective than ketotifen and terfenadine in inhibiting histamine-induced skin wheal in rats, when the drugs were administered intravenously. However, epinastine has been reported to be less effective than ketotifen and mepyramine in inhibiting anaphylactic histamine release from rat peritoneal mast cells (3).

The activated neutrophils generate superoxide anion $\left(\mathrm{O}_{2}{ }^{-}\right) . \mathrm{O}_{2}^{-}$is generated primarily through the activation of the plasma membrane-bound NADPH oxidase system containing FAD, cytochrome $b_{s \$ 8}$ (4) and other cytosolic soluble proteins (5). There is some evidence that $\mathrm{O}_{2}{ }^{-}$may be responsible for allergic reactions such as asthma (6). There are only a few reports that have examined the relationship between $\mathrm{O}_{2}^{-}$and antiallergic drugs. In this study, we examined the effects of epinastine, ketotifen, oxatomide, mequitazine and cromolyn sodium on the $\mathrm{O}_{2}{ }^{-}$generation from the rat neutrophils, using cypridina luciferin analog (MCLA)-dependent chemilumines-

\footnotetext{
* To whom correspondence should be addressed.
}

cence as a probe for $\mathrm{O}_{2}^{-}$generation.

Male Wistar rats (SLC, Hamamatsu), each weighing 300 to $400 \mathrm{~g}$, were used. Under ether anesthesia, whole blood was collected from the carotid artery and diluted twice with Hanks' balanced salt solution (HBSS) $(\mathrm{pH}$ 7.4). Neutrophils were purified to a level higher than $85 \%$ by Percoll (Pharmacia Biotech, Uppsala, Sweden) density gradient centrifugation. $\mathrm{O}_{2}^{-}$generation by rat neutrophils was measured by the MCLA (Tokyo Kasei Kogyo Co., Ltd., Tokyo)-dependent chemiluminescence method (7). Neutrophil suspensions $\left(10^{6} \mathrm{cells} / \mathrm{ml}\right)$ were incubated for $3 \mathrm{~min}$ in HBSS containing $0.4 \mathrm{mM}$ of MCLA and various concentrations of antiallergic drugs at $37^{\circ} \mathrm{C}$ in the dark. Cell suspensions were transferred into a glass vial, and then photon counting was started. Five seconds later, $N$-formyl-Met-Leu-Phe (fMLP; Sigma Chemical Co., Ltd., St. Louis, MO, USA) $(2.5 \mu \mathrm{M})$ or phorbol 12 myristate 13-acetate (PMA; Sigma Chemical Co., Ltd.) $(20 \mu \mathrm{g} / \mathrm{ml})$ was added into the vial. MCLA-dependent chemiluminescence was monitored with a Lumicounter ATP-237 (Advantec Co., Ltd., Tokyo).

Cell disruption was carried out according to the previously described method (8). Disrupted cells were centrifuged at $1,000 \times \mathrm{g}$ for $10 \mathrm{~min}$ at $4^{\circ} \mathrm{C}$ to remove unbroken cells, nuclei and large debris. The supernatant was centrifuged at $135,000 \times g$ for $1 \mathrm{hr}$ at $4^{\circ} \mathrm{C}$. The pellet containing the membrane fraction was incubated with each 
drug for $3 \mathrm{~min}$ at $37^{\circ} \mathrm{C}$ and then centrifuged at $135,000 \times g$ for $1 \mathrm{hr}$ at $4^{\circ} \mathrm{C}$. The pellet was mixed with the $135,000 \times \mathrm{g}$ supernatant. FAD (Sigma Chemical Co., Ltd.), sodium dodecyl sulfate (SDS; Sigma Chemical Co., Ltd.) and MCLA were added, and photon counting was started. Five seconds later, $10 \mathrm{mM}$ NADPH (Sigma Chemical Co., Ltd.) was added to initiate $\mathrm{O}_{2}^{-}$-generation. The assay was done in the Lumicounter ATP-237.
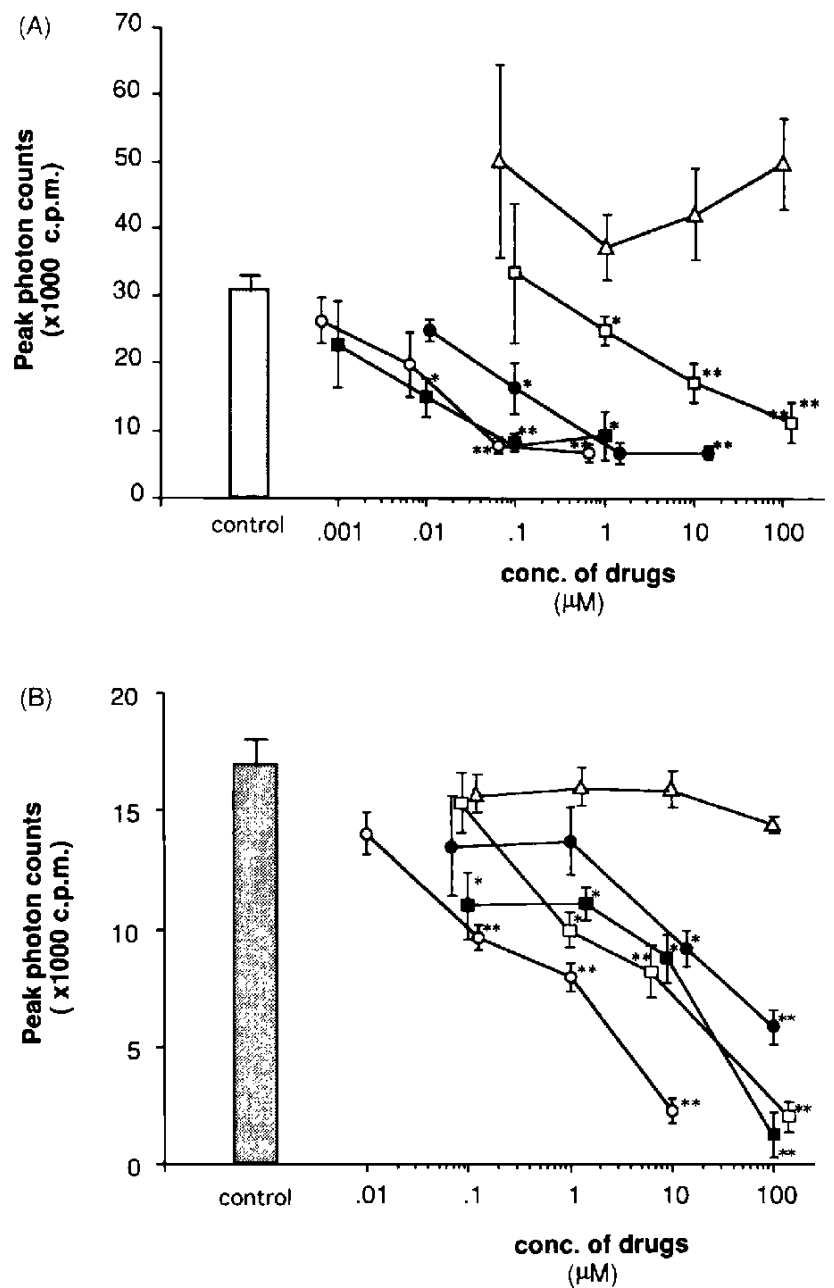

Fig. 1. Effects of epinastine $(\bigcirc)$, oxatomide (O), cromolyn sodium ( $\triangle$ ), mequitazine $(\square)$ and ketotifen $(\square)$ on the generation of superoxide anion $\left(\mathrm{O}_{2}^{-}\right)$induced by $N$-formyl-Met-Leu-Phe (fMLP) and phorbol 12-myristate 13-acetate (PMA) by rat neutrophils. Neutrophil suspensions $\left(10^{6} \mathrm{cells} / \mathrm{ml}\right)$ were incubated for $3 \mathrm{~min}$ in Hanks' balanced salt solution (HBSS) containing MCLA $(0.4 \mu \mathrm{M})$ and various concentrations of anti-allergic drugs at $37^{\circ} \mathrm{C}$, and fMLP $(2.5 \mu \mathrm{M})$ (A) or PMA $(20 \mu \mathrm{g} / \mathrm{ml})$ (B) was added. A: Epinastine, oxatomide, mequitazine and ketotifen dose-dependently inhibited fMLP-induced $\mathrm{O}_{2}{ }^{-}$generation. The $\mathrm{IC}_{50}$ was $0.03,0.27,14.59$ and $0.03 \mathrm{mM}$, respectively. B: Epinastine, oxatomide, mequitazine and ketotifen also dose-dependently inhibited PMA-induced $\mathrm{O}_{2}{ }^{-}$generation. The $I C_{50}$ was $5.23,49.41,6.09$ and $0.76 \mathrm{mM}$, respectively. Each point indicates the mean \pm S.E. $(\mathrm{n}=8) .{ }^{*} \mathrm{P}<0.05,{ }^{* *} \mathrm{P}<0.01$ vs control.
The results are reported as the means \pm standard error of the means (S.E.). Statistical significance was evaluated by the unpaired Student's $t$-test, with $\mathrm{P}<0.05$ being regarded as significant. $\mathrm{IC}_{50}$ values were calculated according to the method of Litchfield-Wilcoxon.

Addition of fMLP at concentrations between 0.4 and $40 \mu \mathrm{M}$ increased the peak photon counts of MCLAdependent chemiluminescence in a dose-dependent fashion $(9045-42780 \mathrm{cpm})$. Pretreatment with superoxide dismutase (SOD, $1-100 \mathrm{U} / \mathrm{ml}$ ) dose-dependently inhibited these increases $(3860-2415 \mathrm{cpm}$ vs $30885 \mathrm{cpm}$ at $\operatorname{SOD}(-))$. Figure $1 \mathrm{~A}$ shows the inhibitory effects by epinastine, oxatomide, mequitazine and ketotifen on
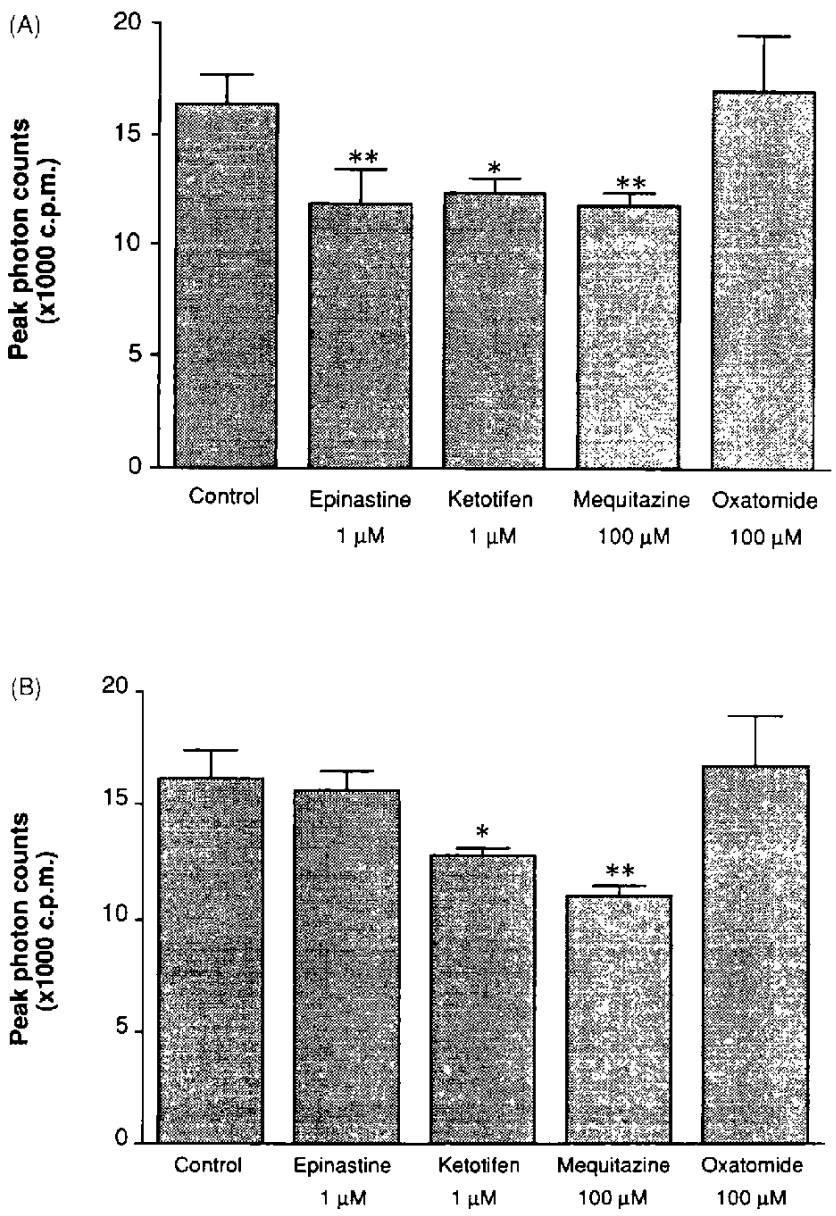

Fig. 2. Effects of epinastine, ketotifen, mequitazine and oxatomide on sodium dodecyl sulfate (SDS)-induced $\mathrm{O}_{2}{ }^{-}$generation in the reconstructed NADPH oxidase system by rat neutrophils. Drugs were used at the maximal inhibitory concentration in the intact cells. A: Membrane and cytosol fractions were preincubated with each drug for $3 \mathrm{~min}$ at $37^{\circ} \mathrm{C}$, and FAD, MCLA, SDS and NADPH were added. B: The membrane fraction was incubated with each drug for $3 \mathrm{~min}$ at $37^{\circ} \mathrm{C}$ and then centrifuged at $135,000 \times \mathrm{g}$ for $1 \mathrm{hr}$ at $4^{\circ} \mathrm{C}$. The pellet was mixed with the cytosol fraction, FAD, MCLA, SDS and NADPH. Each point indicates the mean \pm S.E. $(n=8)$. ${ }^{*} P<0.05$, ${ }^{* *} \mathrm{P}<0.01$ vs control. 
fMLP-induced $\mathrm{O}_{2}^{-}$generation from rat neutrophils. The $\mathrm{IC}_{50}$ was $0.03,0.27,14.59$ and $0.03 \mu \mathrm{M}$, respectively. However, cromolyn sodium could not prevent $\mathrm{O}_{2}{ }^{-}$ generation. On the other hand, epinastine, oxatomide, mequitazine and ketotifen also prevented PMA-induced $\mathrm{O}_{2}{ }^{-}$generation in a dose-dependent fashion (Fig. 1B), with an $\mathrm{IC}_{50}$ of $0.52,49.41,6.09$ and $0.76 \mu \mathrm{M}$, respectively. Cromolyn sodium was also unable to prevent PMA-induced $\mathrm{O}_{2}{ }^{-}$generation.

The $1,000 \times g$ supernatant of the disrupted neutrophils could generate $\mathrm{O}_{2}^{-}$when it was stimulated by SDS $(100 \mu \mathrm{M}: 16137 \pm 1289 \mathrm{cpm}$ vs $645 \pm 58 \mathrm{cpm})$, but the $135,000 \times g$ supernatant could not generate $\mathrm{O}_{2}{ }^{-}$. When the membrane and cytosol fractions were pretreated with antiallergic drugs, $\mathrm{O}_{2}^{-}$generation was significantly prevented by epinastine, ketotifen and mequitazine. However, oxatomide did not inhibit it (Fig. 2A). On the other hand, when only the membrane fraction was pretreated, $\mathrm{O}_{2}{ }^{-}$generation was not prevented by epinastine, but prevented by ketotifen and mequitazine (Fig. 2B).

Nakano showed that MCLA reacted with $\mathrm{O}_{2}{ }^{-}$or ${ }^{1} \mathrm{O}_{2}$ to emit light, probably via the dioxetanone analog (7). SOD or $\mathrm{NaN}_{3}$ can be used to differentiate between $\mathrm{O}_{2}{ }^{-}-$and ${ }^{1} \mathrm{O}_{2}$-dependent luminescence (7). In this experiment, we examined the effect of antiallergic drugs on the $\mathrm{O}_{2}{ }^{-}$ generation by rat neutrophils using MCLA-dependent chemiluminescence as a probe of $\mathrm{O}_{2}{ }^{-}$generation. fMLP increased MCLA-dependent chemiluminescence in a dose-dependent fashion, which was extinguished by SOD, and the luminescence was not affected by the presence of $\mathrm{NaN}_{3}\left(1 \mathrm{mM}\right.$ ), a quencher of ${ }^{1} \mathrm{O}_{2}$ (data not shown). These findings suggested that this assay system using MCLA could measure only $\mathrm{O}_{2}{ }^{-}$, and MCLA-dependent chemiluminescence were not contaminated with ${ }^{1} \mathrm{O}_{2}$.

Antiallergic drugs with $\mathrm{H}_{1}$-receptor antagonism, epinastine, oxatomide, mequitazine and ketotifen, abolished the MCLA-dependent luminescence from rat neutrophils induced by FMLP and PMA in a dose-dependent fashion, but cromolyn sodium, without $\mathrm{H}_{1}$-receptor antagonism, did not abolish it. These findings suggest 1) that these drugs trap $\mathrm{O}_{2}{ }^{-}$from neutrophils in the medium or 2) that the drugs inhibit the $\mathrm{O}_{2}{ }^{-}$generating NADPH-oxidase system. To determine whether these drugs act as a scavenger or not, we examined the effect of $\mathrm{KO}_{2}$ that generates $\mathrm{O}_{2}$ chemically. Consequently, it was found that epinastine, oxatomide, mequitazine and ketotifen have no effect on $\mathrm{O}_{2}{ }^{-}$itself (data not shown), and these drugs may not be able to trap $\mathrm{O}_{2} \cdots$. Therefore, we studied whether these drugs might affect NADPH oxidase directly or not. The $1,000 \times \mathrm{g}$ supernatant of the disrupted neutrophils containing the membrane and cytosol fractions could generate $\mathrm{O}_{2}{ }^{-}$when it was stimulated by SDS, but the $135,000 \times g$ supernatant containing only the cytosol fraction could not. However, when the $135,000 \times \mathrm{g}$ pellet was mixed with the supernatant, the $\mathrm{O}_{2}{ }^{-}$generation was elicited (9). The NADPH-oxidase system contains membrane associated proteins such as cytochrome $b_{5 s 8}$ and cytosolic proteins such as p47-phox and p67-phox $(5,10-12)$, and the activation of NADPH oxidase in the cell-free system requires the association of several cytosolic components together with membrane associated cytochrome $b_{558}(5)$. Therefore, using a $1,000 \times g$ supernatant, FAD, NADPH and SDS as both membrane solubilizer and stimulant of this system, we examined the direct inhibitory effect of these drugs on the NADPHoxidase system. When both membrane and cytosolic components were pretreated with epinastine, ketotifen, mequitazine and oxatomide, epinastine, ketotifen and mequitazine inhibited $\mathrm{O}_{2}{ }^{-}$generation by the SDS-stimulated NADPH-oxidase system, but oxatomide did not. Epinastine, ketotifen and mequitazine might have a direct inhibitory effect on the $\mathrm{O}_{2}{ }^{-}$generating-NADPH oxidase system. Ketotifen and mequitazine inhibited superoxide generation from the NADPH-oxidase system that was reconstructed from the membrane fraction exposed to the drug, the cytosol fraction, FAD, NADPH and SDS, but epinastine and oxatomide did not affect this NADPH oxidase system. Ketotifen and mequitazine have been shown to decrease membrane fluidity (13). The NADPHoxidase system may be partially inhibited due to the membrane stabilizing action of these drugs. However, epinastine had no influence on the membrane fluidity (2). Epinastine augmented the adenylate cyclase activity, and inhibited $\mathrm{Ca}^{2+}$ release from the intracellular $\mathrm{Ca}$ store of rat peritoneal mast cells and calmodulin activity (2). The increase in cyclic AMP content prevents $\mathrm{O}_{2}{ }^{-}$generation from neutrophils (unpublished data, N. Fukuishi and M. Akagi), and the initiation of $\mathrm{O}_{2}{ }^{-}$generation may be attributable to the $\mathrm{Ca}^{2+}$-calmodulin dependent process(es) (14). Therefore, epinastine may partially inhibit $\mathrm{O}_{2}{ }^{-}$ generation through the increase in cyclic AMP content and the inhibition of a $\mathrm{Ca}^{2+}$-calmodulin dependent process(es).

In conclusion, our studies suggest that epinastine may inhibit NADPH oxidase through the inhibition of cytosolic proteins, p67-phox and p47-phox, and ketotifen and mequitazine, through the obstruction of membrane-associated factors, cytochrome $b_{558}$. On the other hand, oxatomide may inhibit superoxide generation through an indirect influence on the NADPH oxidase system.

\section{Acknowledgments}

This research was supported in part by a Grant-in-Aid from the Ministry of Education, Science and Culture, Japan (No. 05671858). 


\section{REFERENCES}

1 Tasaka K, Akagi M, Izushi K and Aoki I: Antiallergic effect of epinastine: the elucidation of the mechanism. Pharmacometrics 39, 365-373 (1990)

2 Kamei C, Akagi M, Mio M, Kitazumi K, Izushi K, Masaki S and Tasaka K: Antiallergic effect of epinastine (WAL $801 \mathrm{CL}$ ) on immediate hypersensitivity reactions: (I) Elucidation of the mechanism for histamine release inhibition. Immunopharmacol Immunotoxicol 14, 191-205 (1992)

3 Fugner A, Bechtel WD, Kuhn FJ and Mierau J: In vitro and in vivo studies of the non-sedating antihistamine epinastine. Arzneimittelforschung 38, 1446- 1453 (1988)

4 Babior BM and Kipness RS: Superoxide-forming enzyme from human neutrophils: Evidence for a flavin requirement. Blood 50, $517-524$ (1977)

5 Abo A, Boyhan A, West I, Thrasher AG and Segal AW: Reconstitution of neutrophil NADPH oxidase activity in the cell-free system by four components: p67-phox, p47-phox, p21racl, and cytochrome b245. J Biol Chem 267, 16767-16770 (1992)

6 Oyanagui Y: Participation of superoxide anions at the prostaglandin phase of carrageenan foot-oedema. Biochem Pharmacol 25, 1465-1472 (1976)

7 Nakano M: Determination of superoxide radical and singlet oxygen based on chemiluminescence of luciferin analogs. Methods Enzymol 186, 585-591 (1990)

8 Bromberg Y and Pick E: Activation of NADPH-dependent superoxide production in a cell-free system by sodium dodecyl sulfate. J Biol Chem 260, 13539-13545 (1985)

9 Seligmann EB, Fletcher PM and Gallin IJ: Histamine modulation of human neutrophil oxidative metabolism, locomotion, degranulation and membrane potential changes. J Biol Immunol 130, 1902-1909 (1983)

10 Knaus UG, Heyworth PG, Evans T, Curnutte JT and Bokoch GM: Regulation of phagocyte oxygen radical production by the GTP-binding protein rac 2. Science 254, 1512-1515 (1991)

11 Abo A, Pick E, Hall A, Totty N, Teahan CG and Segal AW: Activation of the NADPH oxidase involves the small GTPbinding protein p-21 rac-1. Nature 353, 668-670 (1991)

12 Parkand AW and Babior BM: The translocation of respiratory burst oxidase components from cytosol to plasma membrane is regulated by guanine nucleotides and diacylglycerol. $\mathrm{J}$ Biol Chem 267, 19901- 19906 (1992)

13 Akagi M, Mio $M$ and Tasaka K: Antiallergic effects of terfenadine on immediate type hypersensitivity reactions. Immunopharmacol Immunotoxicol 9, 257-279 (1983)

14 Al-Mohanna FA and Hallett MB: The use of fura-2 to determine the relationship between cytoplasmic free $\mathrm{Ca}^{2+}$ and oxidase activation in rat neutrophils. Cell Calcium 9, 17-26 (1988) 